\title{
Design and Implementation of Office Supplies Purchase Examination and Approval System Based on CRP Digital Campus Information Management Platform
}

\author{
Binwen Huang ${ }^{1,}$,, Yuan Jiao ${ }^{2, b}$ \\ ${ }^{1}$ Information Technology Department, Hainan Vocational College of Political Science and Law, \\ Haikou 571100, China \\ ${ }^{2}$ Information Technology Department, Hainan Medical University, Haikou 571199, China \\ a64471362@qq.com, b346607651@qq.com
}

\begin{abstract}
Keywords: Office supplies purchase examination and approval system; Office supplies purchase; CRP digital campus information platform.
\end{abstract}

\begin{abstract}
Office supplies purchase is an indispensable part in enterprises and institutions, in view of the existing problems of school office supplies purchase management such as unclear accounts and office supplies hoarding etc., J. Office collaborative developing platform which is integrated to CRP digital campus information management platform is used to design and implement office supplies purchase examination and approval system. It realizes informatization management and solves existing problems in office supplies purchase management.
\end{abstract}

\section{Introduction}

Office supplies management is an indispensable part in enterprises and institutions, its main purpose is to provide a variety of office items required by each department, with a minimum of material reserve to achieve the best use of state and the reasonable organization of supply, avoid overstock and shortage of goods to ensure the normal operation of the unit office. Because the office supplies are small and miscellaneous items, it is not included in informatizaiton management in most schools, it has been using manual accounting, so artificial loss or duplication often happen during office supplies management, storage management includes entering-warehouse management, out-of-warehouse management, stock management, statistic and inquiry is not timely and accurate, it will lead to emergency items out of stock and not commonly used items excessive hoarding[1].

Most schools still use the paper examination and approval method for the office supplies purchase examination and approval management, staff fills out the paper office supplies purchase examination and approval form, and then the paper form is submitted to approver of different levels for approval, finally, buyer will purchase all office supplies that are approved from different channels. This paper and manual examination and approval method exists a lot of issues: firstly, it leads that the applicant and the approver are time-consuming and inefficient [2], approver is often busy, be on a business trip and study cases often happen, a lot of work can't be follow-up and has been delayed due to lack of timely approval; secondly, paper office supplies purchase examination and approval file is also easy to lose in the transfer process and hard to permanently save[3]; thirdly, storage informatizaiton management can't utilize purchase details from examination and approval system as entering-warehouse data automatically. Through the informatization management of office supplies to, strengthen the strict management of each link of office supplies, reduce management costs, analyze all kinds of statistics, discover and correct all kinds of problems existing in the management of office supplies, and provide timely decision-making information to the office supplies management, so as to achieve scientific and advanced office supplies management. 


\section{Office Supplies Purchase Examination and Approval Process Introduction of CRP Based on J.Office}

The following is office supplies purchase examination and approval process: firstly, applicants fill out application information with required office supplies in the office supplies purchase examination and approval electronic form and start the process via network; secondly, electronic form with application information is submitted to approver of different levels for approval according to fixed examination and approval process; finally, buyer will purchase all office supplies from different channels and update the progress, the purchased office supplies will be as entering-warehouse data and stored into office supplies management system automatically.

\section{Design and Implementation of Office Supplies Purchase Examination and Approval Process Based on CRP - Take Hainan Vocational College of Political Science and Law as Example}

The design and implementation of office supplies purchase examination and approval system using J.Office collaborative development platform can be separated into following three steps:

Office supplies purchase examination and approval electronic form design. In traditional paper and manual examination and approval management, firstly, applicants will fill out the paper office supplies purchase examination and approval form with relevant application information such as applicant department/name/date/cell phone number, office supplies name/specifications/model/ unit price/amounts/price; secondly, different levels approver will make comments in paper examination and approval form, such as department head audit, buyer audit, logistics department head audit, financial department audit and vice-president approval; thirdly, tractors will handle according to approval comments, such as logistics department head handling and buyer handling. The same, we need to design electronic office supplies purchase examination and approval form matching with paper form, it calls paper form digitization. The following is how to use form design machine of J. Office to design the electronic form of office supplies purchase examination and approval system:

Start form design machine of J. Office, select “process” sub menu under "system” menu, and then click "process form" option to open form design machine to design office supplies purchase examination and approval electronic form, we can click "add form" option to add a new form, the new added form is named as "office supplies purchase examination and approval form”.

We can select appropriate controls according to each column attribute of office supplies purchase examination and approval form in form design machine of J. Office, there are various office supplies purchase examination and approval related information column needed to be designed, we can choose "department selector" for applicant department column, "personnel selector" for applicant name column, "timer selector" for application date, "single line text editor" for applicant cell phone number, office supplies name/specifications/model/unit price/amounts, "comments editor" for the remaining. We can see the office supplies purchase examination and approval electronic form from Fig.1.

Office supplies purchase examination and approval process design. In traditional paper and manual examination and approval management, paper office supplies purchase examination and approval form will be sent to approver according to a fixed process, level by level for approval[4], the same, we need to design a specified electronic office supplies purchase examination and approval process. "Office supplies purchase examination and approval form” will be automatically transferred via network from one link to another link for approval and handling based on specified process. The following is how to use "process design machine" to design and implement electronic office supplies purchase examination and approval process:

Start "process design machine”, select "Process definition” option under "Process” menu, click "online process design" to open "process design machine" to do [3] electronic office supplies purchase examination and approval process design.

Office supplies purchase examination and approval process is consists of many links: "start” link, “department head audit” link, "buyer audit” link, "logistics department head audit” link, "vice 
president approval”, "logistics department head handling”, "buyer handling” and "end” link. We can choose "start node" for "start link", "end node" for "end link", "task node” for other link in "process design machine". As shown in Fig.2, we use line to connect these links. Following is the detailed process:

Applicants fill out "office supplies purchase examination and approval form” and submit the application: applicants need fill out "office supplies purchase examination and approval electronic form" that mentioned above with applicant information, and then this form with application information is sent from the process of the "start" link to "department head audit" link.

Department head audit: Department head will audit the form and make audit comments, process will jump to the "end" link if not passed, and the whole process will finish. If the audit is passed by department head, the process with department head audit comments will transfer to "buyer audit" link.

Buyer audit: Buyer will audit the form and make audit comments, the process will jump to "end" link if not passed, and the whole process will finish. If the audit is passed by buyer, the process with buyer comments will transfer to "logistics department head audit" link.

Logistics department head audit: logistics department head will audit the form and make audit comments, the process will jump to "end" link if not passed, and the whole process will finish. If the audit is passed by logistics department head, the process with logistics department head comments will transfer to "vice president approval” link.

Vice president approval: vice president will audit the form and make approval comments, the process will jump to "end" link if not approved, and the whole process will finish. If it is approved, the process with vice president comments will transfer to "logistics department head handling" link.

Logistics department head handling: logistics department head will assign this purchase task to a buyer. The process with logistics department head comments will transfer to "buyer handling” link.

Buyer handling: buyer will purchased all required office supplies according to examination and approval form and update the purchase progress. The process with handling result will transfer to "end" link when office supplies purchase handling is done.

Office supplies purchase form, office supplies purchase process, approver and handling personnel binding. Approver and handling personnel are fixed for each link in traditional paper office supplies purchase examination and approval process, the same, we also need to assign personnel as approver and handling personnel for each link of process in the J. Office; office supplies purchase form, office supplies purchase process and designated personnel for approver and handling personnel are bound to construct a complete electronic office supplies purchase examination and approval process. Fig.1 is office supplies purchase form, office supplies purchase process, approver and handling personnel binding graph. We set the auditor of "department head audit" link as "next higher level" of applicant, auditor of "logistics department head" and "logistics department handling" as head of "logistics department”, and remaining link as specific personnel.

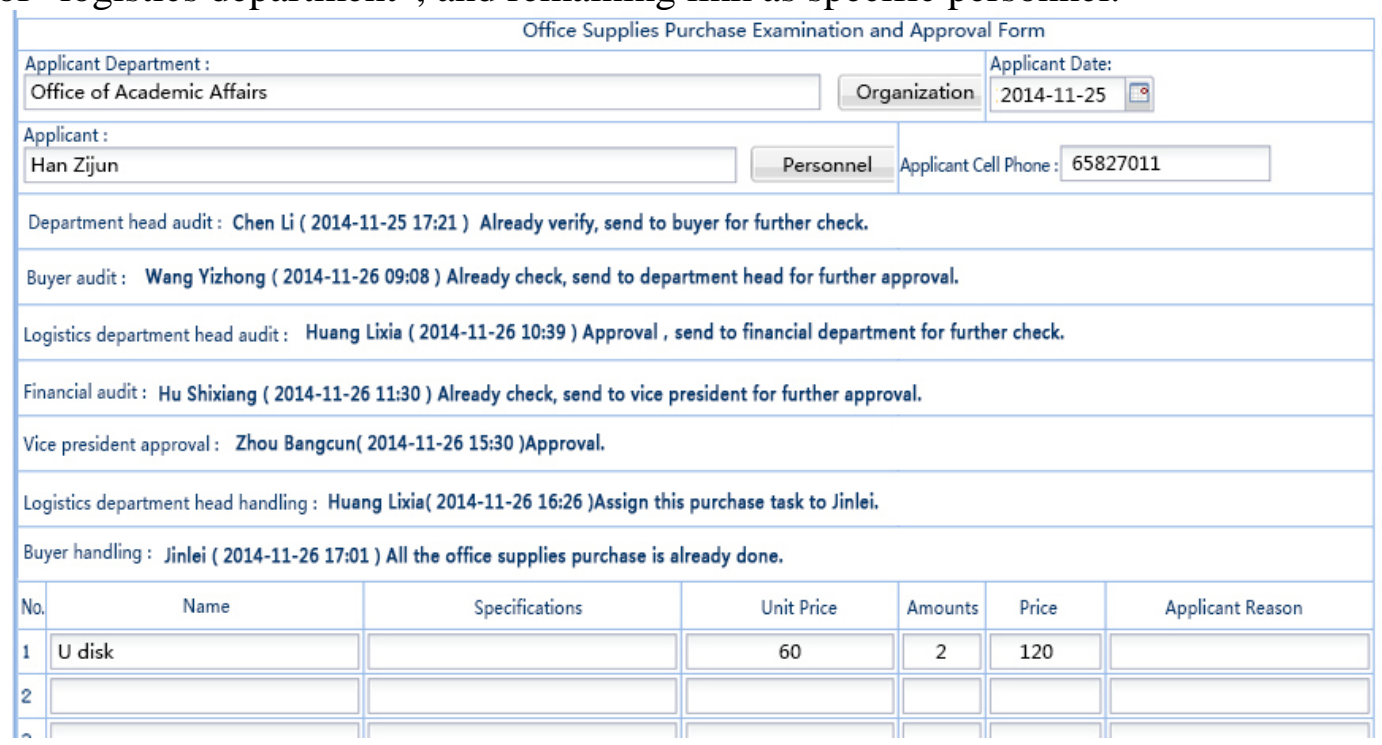


Fig.1 Approval process demon

\section{Office Supplies Purchase Examination and Approval Process Demon}

The demo is shown in Fig.1. The user can query process execution state in real time.

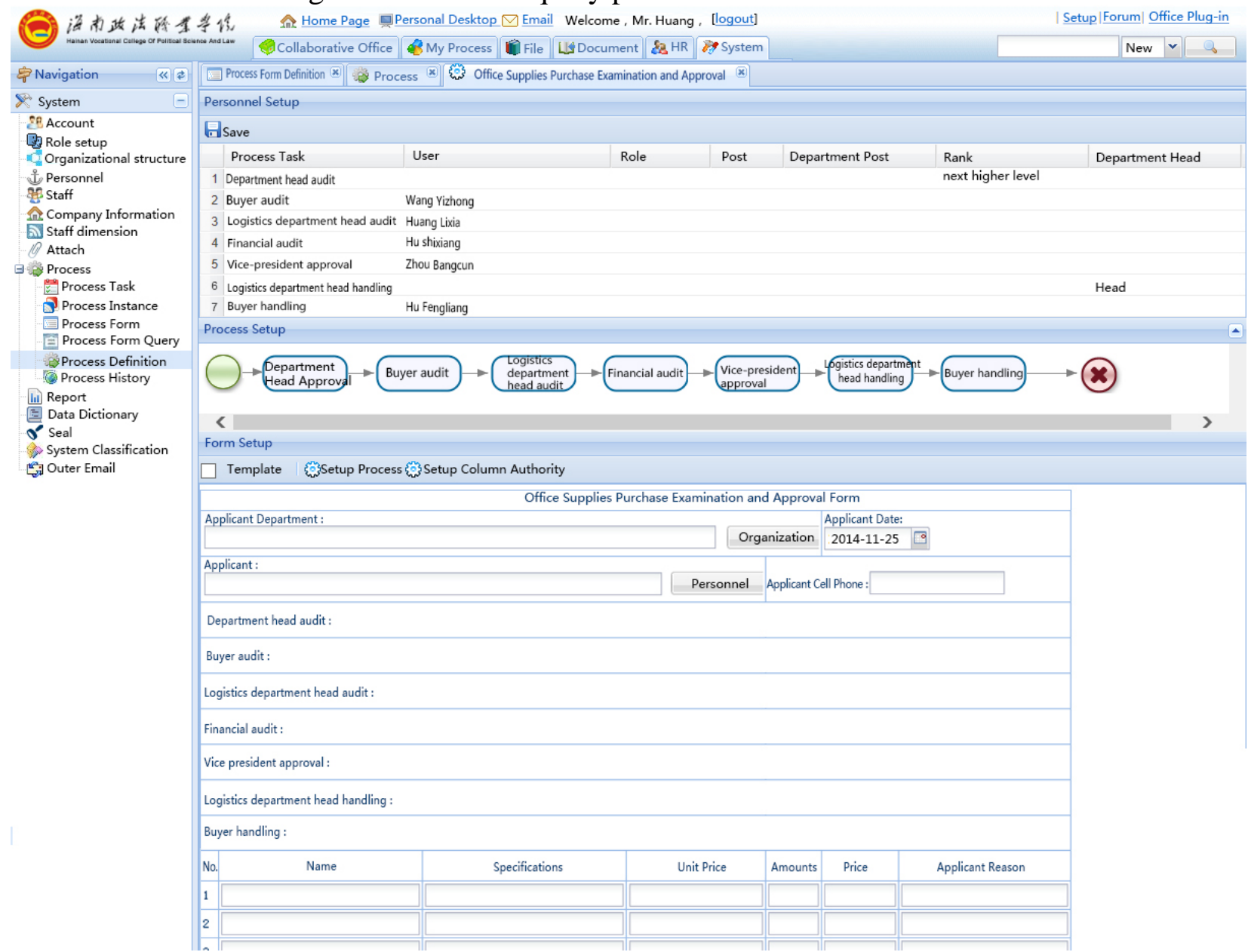

Fig.2 office supplies purchase form, office supplies purchase process, approver and handling personnel binding graph

\section{Acknowledgments}

This work was financially supported by the 2014 Social Science Fund Project of Hainan Province (HNSK14-19).

\section{References}

[1] Deng Baohua: Research and implementation of business process modeling environment in dynamic Web services composition. The national defense science and Technology University, 2005.

[2] Deng Baohua: Research and implementation of business process modeling environment in dynamic Web services composition. The national defense science and Technology University, 2005.

[3] Huang binwen, Jiaoyuan: Design and implementation of CRP digital campus information platform of process examination and approval system. Science and Technology Innovation Herald, 2013 (11).

[4] Huang binwen, Jiaoyuan: Design and Implementation of Network Leave Examination and Approval System Based on CRP Digital Campus Information Management Platform. Applied Mechanics and Materials Vols. 670-671 (2014) pp 1536-1539. 